\title{
MONITORING AND STUDY PROCESS OF GOTHIC BUILDINGS
}

\author{
SERGIO COLL-PLA, GUILLEM MATEU, AGUSTÍ COSTA JOVER \& JAUME ROSET-CALZADA \\ Unitat Pre-departamental d'Arquitectura de la Universitat Rovira i Virgili, Spain
}

\begin{abstract}
The energetic understanding of medieval buildings requires a joint study, because in this building typology, the structure acts as a climatic protection as is known. From another point of view, medieval buildings tend to be grouped in a pineapple, conditioning the climatic and structural understanding. Therefore, the knowledge and study of the old urban models is crucial for their understanding. The urban model and its surroundings determine the climatic demands of the interior spaces. In the same way the construction characteristics and materials. The article aims to develop an open system of hydrothermal measurements that allows hydrothermal comprehension of spaces. The result will be a sensor system with interpretable data that will allow us to understand the hydrothermal system of a medieval building located in its context. The interpretation of these data will allow making a comparison between different construction solutions that allow improving the hydrothermal conditions of the interior according to the climate.
\end{abstract}

Keywords: open source, hydrothermal sensors, temperature, inertia.

\section{INTRODUCTION}

Understanding the energy performance of buildings is essential to adapt to climatic conditions, which is why current regulations respond to these conditions. It should be noted that the regulations are prepared for new buildings or major renovations, especially since the entry into force of the Spanish Technical Building Code. The difficulty of adapting buildings to current energy regulations often undermines the architectural principles of the building. Therefore, the Technical Building Code does not prescribe specific standards for intervention in existing buildings and allows these standards to be waived in heritage buildings. European regulations also exempt heritage buildings from compliance with reducing consumption. Therefore, medieval city centres lose their character in favour of their habitability.

Speaking about city centres, Europe has many medieval city centres. The main feature of medieval urbanism is the occupation of open spaces, especially public spaces. As far as the division of land into plots is concerned, these acts by means of the fragmentation or gathering of neighbouring plots. Specifically, in terms of urban planning, this is the phenomenon of the invasion of private space over public space, of the appropriation of private spaces which have been destroyed in favour of the location of new roads, or more rarely of cleared land. The medieval urbanism has its decline with the book De Re edificatoria (1485) by Leon Batista Alberti. With it, during the Renaissance, the notions of proportion, regularity, symmetry, and perspective gave birth to what in the following centuries would become known as urban art. The purpose is explicitly aesthetic: visual pleasure (the search for beauty) is privileged over necessity and comfort. These ideas spread throughout Europe at the end of the 16th century, finding their end as a dominant tradition in the search for utility imposed by the industrial revolution in the 19th century.

There is currently a considerable amount of medieval building stock, while Spanish building regulations encourage energy efficiency in new and existing buildings. This means that construction solutions accepted by the regulations for new buildings are applied to preindustrial buildings without questioning the energy benefits they bring. It should be borne in mind that these buildings have historical, aesthetic and functional value [1]. Therefore, 
parameter monitoring using technological components is on the increase [2]. The main objective is to generate a system of free access for the study of the climate of old buildings, which will allow us to study the advantages and disadvantages of urban planning and historical buildings in order to optimise their advantages and minimise their disadvantages. This urban planning will condition the architectural typology, as well as the construction details.

\section{OBJECT OF STUDY}

The object of study (Fig. 1) is a building integrated into a medieval urbanism, in this case Gothic, in the town of La Llacuna. This town is mentioned in documents from 987 as belonging to the county of Barcelona. In 1079, it was owned by the Cervelló family, who became the castle's mistress. In 1347, the barony of La Llacuna was formed, a noble title that lasted until the end of the old regime [3].

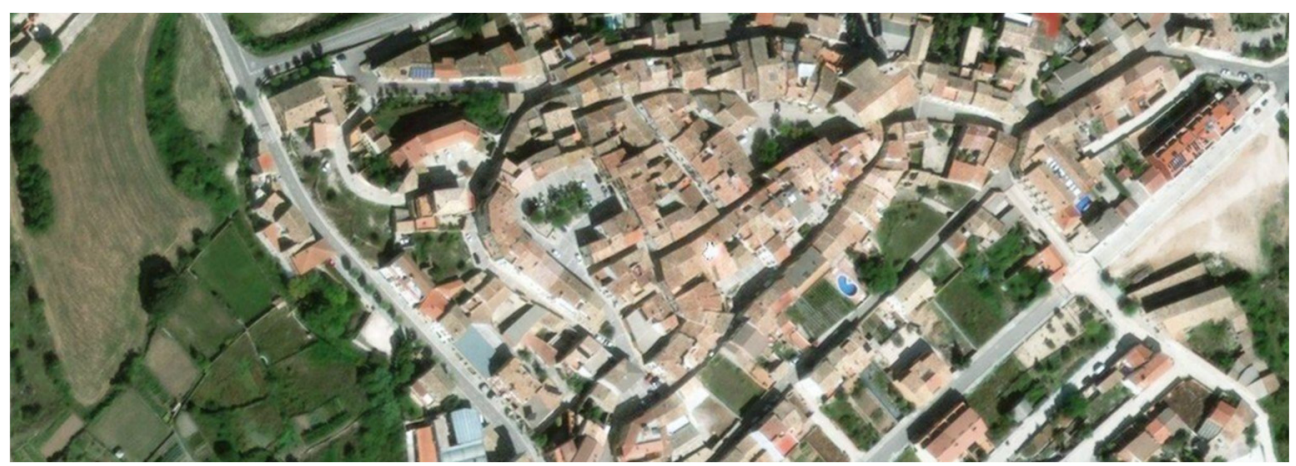

Figure 1: Medieval urbanism of La Llacuna.

The building under study is a building with a gothic elements that has remained unchanged over the last 60 years (Fig. 2), so that it has not suffered any kind of intervention with current materials that provide thermal modifications. The main thermal feature is the conservation of original woodwork and insulation systems.

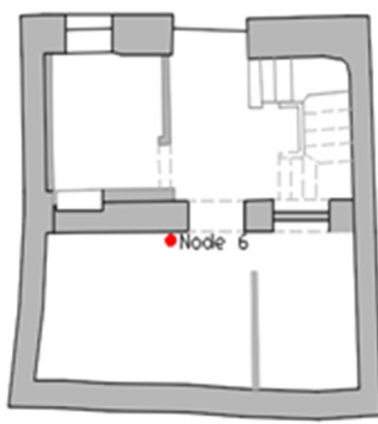

Ground floor plan

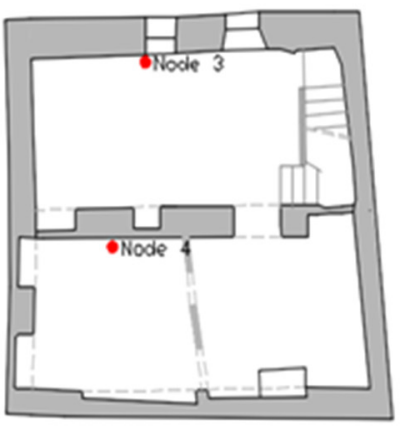

First floor plon

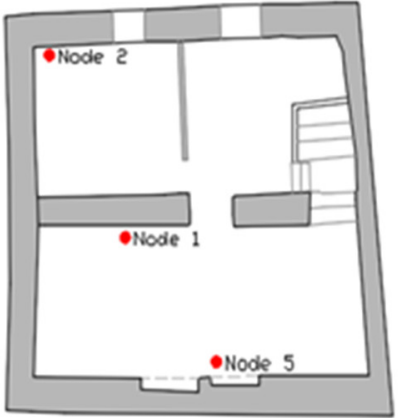

second floor plan

Figure 2: Plants of the building under study and location of the sensors. 


\section{STATE OF THE ART}

A complete study of the building requires an analysis of the history and functions, energy, climate change audit and an evaluation of the compatibility and reversibility of each action [4]. The study will focus on the type of system to be used, as well as the types of sensors to be chosen. Building modelling can be carried out using commercial sensors and systems, the main problem being that they are not modifiable [5]. Therefore, the use of freely available hardware [6] is chosen for the remote collection of climate data [7]. The sensors to be chosen are essential. Francisco Javier Mesas-Carrascosa used temperature and relative humidity sensors in the Mosque-Cathedral of Córdoba [8]. Martin Consuegra studied energy consumption (diesel, electricity) as well as comfort parameters such as interior versus exterior temperature in the main building of the Eduardo Torroja Institute [9]. A complete study refers to the study carried out by Mahdjoubi, where the following sensors are applied: air temperature, relative humidity, $\mathrm{CO}_{2}$ level, sensor of volatile organic components, light sensor and study of energy consumption [1].

\section{DESIGN OF THE SYSTEM}

The study method will take into consideration the objective to be achieved and will require the creation of a system for taking climate data in real time by giving it an internet connection. Another requirement is that the resulting system must be easily expandable and adaptable to any monitoring needs that may be necessary to prevent damage to historic buildings, which is why the Open-Source system is used [10]-[14]. The need to design hardware must also be taken into consideration. This point requires the choice of components, sensors, and microcontrollers to be used.

\subsection{Selected sensors}

The temperature and humidity sensors to be used will be: AM2302 [15], also known as DHT22. This sensor communicates with the microcontroller via a OneWire1 communication bus. According to the manufacturer's specifications, this sensor allows us to measure humidity from $0 \%$ to $99.9 \%$ with an absolute error of $2 \%$ and a resolution of 0.1 . As for the temperature, it has a range between $-40^{\circ} \mathrm{C}$ and $80^{\circ} \mathrm{C}$ with an absolute error of $0.5^{\circ} \mathrm{C}$ and a resolution of 0.1; AM2320 [16]: This sensor is practically the same as the previous one with the difference that it has an absolute error of 3\% humidity and that, besides being able to communicate in OneWire protocol, it can be connected to an I2C bus.

The tilt sensors to be used will be the chosen sensor is the ADXL345 [17]. It is a threeaxis accelerometer that allows us to obtain two inclination angles. It gives us the readings in digital format through an $\mathrm{I} 2 \mathrm{C}$ or SPI bus, eliminating the need to add an ADC2. Furthermore, it allows us to reach a resolution of $3.9 \mathrm{mg}^{3}$ thanks to which we will be able to detect changes in the inclination of less than $1{ }^{\circ} \mathrm{C}$. We will use a module called GY-291. This module has the sensor soldered onto a board, as well as additional passive components and allows us to make the connections through pins that are much more convenient to use on prototype boards. With trigonometry, we can find the angles that we want to calculate from the reading of the clarification in each axis. Specifically, the formulas we have used are as follows:

Monitoring the opening of a crack once its appearance has been detected can be very important, since small variations undetectable to the naked eye or even with basic measurement tools, can be useful in detecting movements of the building before irreparable damage occurs. It is interesting to be able to reference this measurement with the ambient temperature, as it will allow us to see how this affects expansion by seeing the differences throughout the day or between seasons. To measure linear displacement, we have decided to 
do so with an LVDT4. It is an absolute linear displacement transducer that has a very high precision and a very low hysteresis. The LVDT we have chosen is the SM1 from Solartron Metrology; we have chosen this model because of its lower price. It has a lower travel than others $(1 \mathrm{~mm})$, but we do not need more, as if the crack exceeds this opening the situation would be critical anyway.

The measurement of the surface temperature is interesting to check the thermal inertia of the walls. Our intention is to measure it on the interior and exterior surface of the façade and see the variation throughout the day and between seasons. For this measurement we have chosen to use thermocouples because of their low cost and the ease with which they can be mounted on any surface with the appropriate adhesive. Its low mass makes its thermal inertia negligible and its temperature is the same as the surface on which it is in contact. Thermocouples consist of the union of two conductors made of different metals. This union produces a voltage difference that varies according to the temperature at each of the ends. When using them, it must be considered that another temperature sensor is needed to compensate for the reference temperature. Thermocouples have a very large measurement range, up to thousands of degrees Celsius, and along this range they do not have a linear behaviour.

By isolating, we obtain the equation of the temperature as a function of the stress, the temperature of the cold junction, and the Seebeck coefficient. We will use type $\mathrm{K}$ thermocouples, which have a coefficient of $41 \mathrm{~V} /{ }^{\circ} \mathrm{C}$.

To connect the thermocouples in the microcontroller, we have done so with an ADS1118. This chip is an ADC of the same family as the ADS1115 [18] that we use for LVDT measurement. The difference is that the ADS1118 includes an internal temperature sensor that can be used to compensate for the cold junction temperature of the thermocouples. If we conjure it up to obtain the maximum possible resolution, which is $7.8125 \mathrm{~V}$, we will have a resolution of approximately $0.2^{\circ} \mathrm{C}$ in the temperature measurement.

\subsection{Hardware design}

When monitoring the environment health of a building, we often find ourselves in the situation where we must take measurements in multiple locations, in some cases we may be close (measuring temperature at different points on the surface of a wall), other times we may be distant (ambient temperature in different rooms or floors). It would not be surprising to develop sensors where those that are the farthest apart are tens of meters away. That is why it is not viable to have a single microcontroller making the readings of all the sensors.

On the one hand, the distances are too great for the communication buses used by some sensors to work without problems (due to voltage drops and very high capacitances because of very long cables).

On the other hand, it is likely that, as we are dealing with historical buildings, for reasons of aesthetics or conservation, we will not be allowed to install many cables in sight or make holes in the walls to pass them through, and we will be asked to keep the number of visible system elements to a minimum. It is therefore clear that the solution is to use communication without cables. The option chosen is radiofrequency, specifically Wi-Fi technology, because the wide range of hardware available makes it an economical option and the amount of documentation available makes it an easy option to implement. Our network will have two nodes, one of them will act as a bridge between the local network and the Internet.

We have sensors distributed in six nodes (Fig. 3). This allows us to distribute them as we see fit throughout the building where they are easy to install: Node 1 consists of a NodeMCu plate with two different environmental temperature and humidity sensors, one of which is an 
AM2302 and the other an AM2320. Each is connected to a OneWire bus; Node 2 apart from the temperature and humidity sensor AM2302 and AM2320, this node also includes the accelerometer for measuring the inclination of a wall. Like the previous one, it uses a NodeMCU board; Node 3 is like the other two previous nodes: NodeMCU board and temperature and humidity sensors AM2302 and AM2320. It also measures the two surface temperatures using two thermocouples; Nodes 4, 5, 6 are identical, only using an AM2320 sensor to measure temperature and humidity. As they only use one sensor, we have chosen to use an ESP-01 module, which is cheaper than a development board.

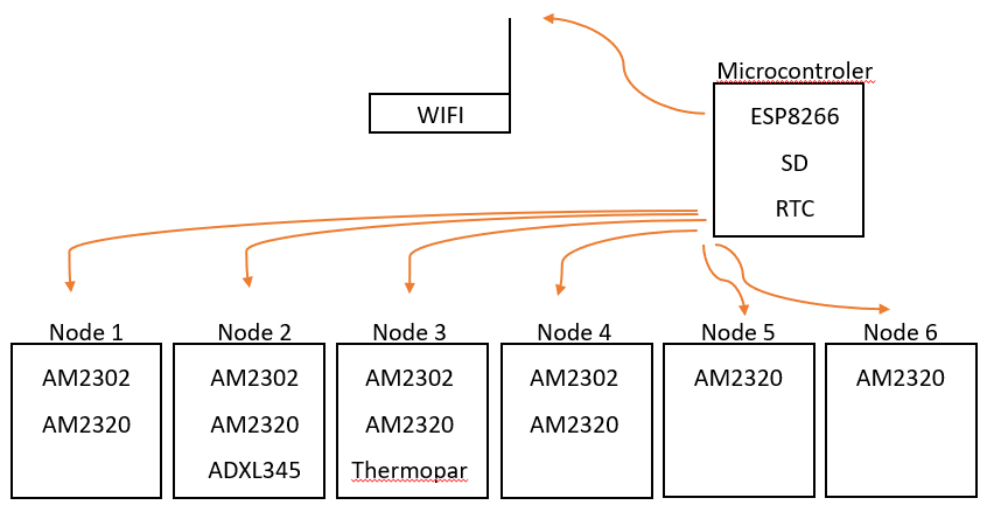

Figure 3: Scheme of monitoring system.

\subsection{Design of the network structure}

The ESP8266 is a $\mathrm{SoC}^{6}$ (Fig. 3) that integrates a 32-bit microcontroller and components required for $2.4 \mathrm{GHz}$ Wi-Fi connectivity: as well as other peripherals common to most microcontrollers such as UART, $\mathrm{I}^{2} \mathrm{C}, \mathrm{PWM}$ and $\mathrm{ADC}$.

The use of these chips has been widespread since its creation thanks to the Maker community, which saw potential in it and immediately integrated it into the Arduino environment making it compatible with the hundreds of existing libraries, making its use in hobbyist projects skyrocket. It is because of this large amount of information, documentation, libraries, and examples; as well as his low cost and previous experience, which we have chosen him for this project.

The system is complemented with a SD memory card and a Real-time Clock.

\section{RESULT}

The results obtained from August 2nd to February 15th (Figs 4 and 5) show the evolution of the knots over two days, being shown in node 1: the graph of humidity (range of 51.1-49.6), temperatures (range of 26.7-20.2); in node 2 the graph of humidity (range of 74.2-49.2), temperatures (range of 27-7.3) and inclination (range of 175.59/172.82-175.17/172.27); in node 3 the humidity graph (range of 59.5-64.1), indoor temperature (range of 8.6-25) and outdoor temperature (range of 33.47-6.45); in node 4 the humidity graph (range of 66.566.1 ) and temperature (range of 24.3-8.7); in node 5 the humidity (range 85.2-75.5) and temperature (range 7-9.9) graphs and in node 6 the humidity (range 64.8-70.1) and temperature (range 7.6-22.4) graphs. 


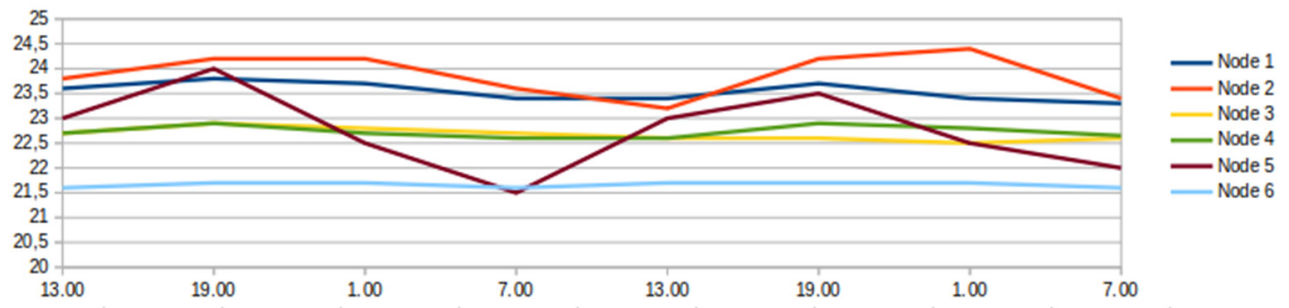

Figure 4: Temperature data of all nodes.

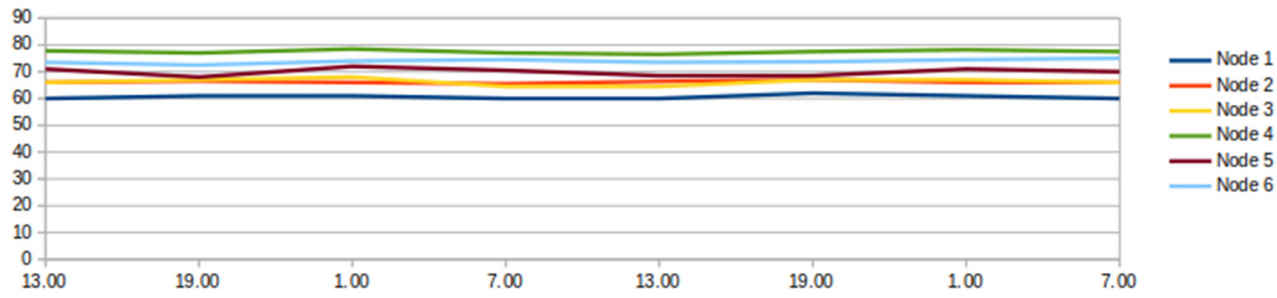

Figure 5: Humidity data of all nodes.

\section{DISCUSSION}

Regarding the system of chosen nodes: If we study the humidity graphics, we see that the nodes with a type of sensor AM2320 have a different reading than those with the sensor AM2302. They do retain the daily oscillation, but not the oscillation range; the expansion and inclination sensors require a complete structural understanding of the building and its environment in this case.

The study of the temperature on August 15 indicates that the inertia of the building is high since the temperature of the ground floor is $23.2^{\circ}$; nodes 3 and 4 located on the first floor have a stable temperature throughout the day of 25.3 and 25.7; nodes 1 and 2 already have the oscillations caused by the outside temperature, however it should be explained that node $1(26.3-26.7)$ is in a room with a ventilated air chamber, avoiding direct radiation; and node $2(27.2-28.2)$ is located in a room with a compact floor without insulation. Node 5, installed in the ventilated air chamber, indicates that this is useful to avoid direct impact from the sun.

The same happens in the study of the temperature on January 15 with the following data: node 6 has a temperature of (7.7), nodes 3 and 4 located on the first floor have a stable temperature throughout the day of 7.3 and 8.4; and node 2 (7.2-8). Node 1 has the same temperature and behaviour as the outside temperature with a range of (6.45-16.11).

If we take a reading from the thermal inertias, we can see that the study of 15 August (Fig. 6), where the outside temperature is generally higher than the inside temperature, node 1 (located in a room with a ventilated air chamber on the roof) is better insulated than node 2 , located in a room with a compact floor on the roof. This same study to January 15 is observed that in the daily study, the sensor 1 even maintaining the oscillation of the inertia, the temperature is near to the outside, on the other hand the node two, also maintains the oscillation, but the temperature is lower. 


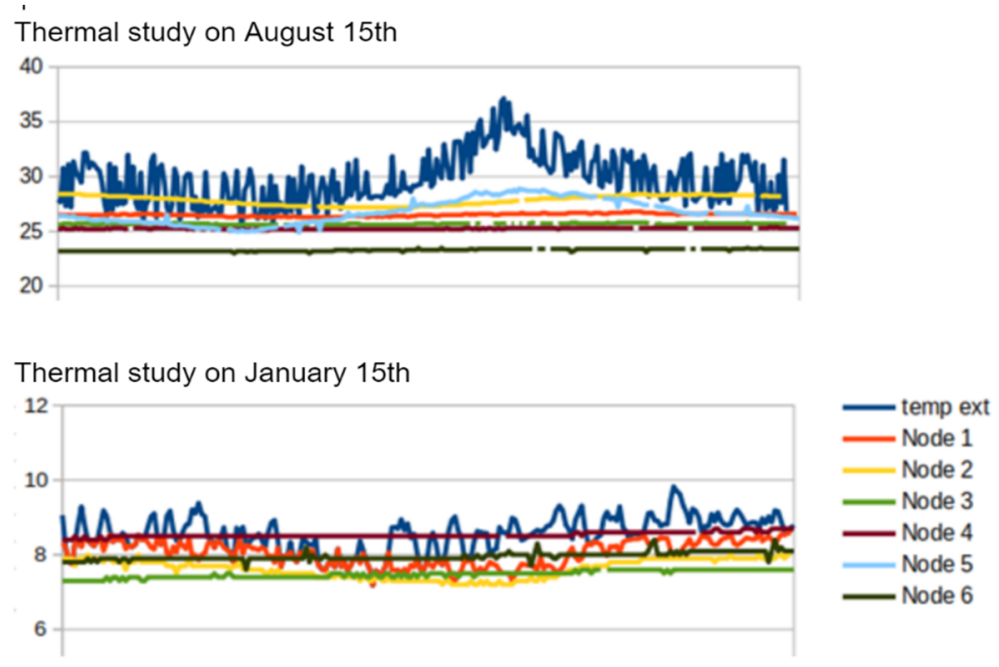

Figure 6: Study of temperature of all nodes.

In summer, nodes 3 and 4 follow the same temperature range, favoured by the low incidence of the sun on the façade and node 6 is the coolest room, the furthest from the façade and the roof. On the other hand, in winter, node 3 (closest to the façade) is the lowest temperature, and node 6 (furthest from the façade and the roof) is the highest temperature.

\section{CONCLUSION}

The system designed for free access is useful for heritage building modelling. One of the main concerns the usefulness of the ventilated roof. In summer, it helps to keep temperatures low and in winter it helps to maintain the temperature interior of the building. A good example of this type of roof is the Catalan-style roof or the ventilated tile roof. So, this is an element to be preserved in the building. The thermal inertia is more favourable in summer than in winter, as studies show that point 6 has a range of difference of $3^{\circ}-15^{\circ}$ with the outside climate and in winter point 6 has a range of difference of $1^{\circ}-2^{\circ}$ with the outside.

The future works, it will be necessary to propose a system that always provides information on the surface temperature of each room, as well as the hygrometric oscillations of the subsurface in the case of humidity on the ground floor.

\section{ACKNOWLEDGEMENTS}

Collaboration, writing and technical assistance are grateful to Melanie Bas, Ferran Modinos, Hajar Oubaddi, Maria Margalef, Pol Fernandez, members of the PATRIARC-CAIT research group.

\section{REFERENCES}

[1] Mahdjoubi, L. et al., A guide for monitoring the effects of climate change on heritage building materials and elements, 2017.

[2] Llie, M., Smith, R., Reed, J. \& Inglis, R., Southwest Scottish crannogs: Using in situ studies to assess preservation in wetland archaeological context. Journal of Archaeological Science, 35, pp. 1886-1900, 2008.

[3] AAVV, Enciclopedia Catalana. Accessed on: Aug. 2020. 
[4] Lucchi, E., Energy efficiency in historic building: A tool for analysing the compatibility, integration and reversibility of renewable energy technologies. World Renewable Energy Congress. Sweden. Low-Energy Architecture (LEA), 2011.

[5] Diego, F.J.C., Esteban, B. \& Merello, P., Design of hybrid (wired/wireless) acquisition data system for monitoring of cultural heritage physical parameters in smart cities. Sensors, 15, pp. 7246-7266, 2015.

[6] Faugel, H. \& Bobkov, V., Open source hard and software: Using Arduino to keep old hardware running. Fusion Engineering, 88, pp. 1276-1279, 2015.

[7] Leccese, F. et al., A new acquisition and imaging system for environmental measurements: An experience on the Italian cultural heritage. Sensors, 14, pp. 9290 9312, 2014.

[8] Mesas-Carrascosa, F.J., Verdú Santano, D., Meroño de Larriva, E., Ortiz Cordero, R., Hidalgo Fernangez, R.E. \& Garcia-Ferrer, A., Monitoring heritage building with opensource hardware sensors: A case of the Mosque-Cathedral of Córdoba. Sensors, 16, p. 1620, 2016.

[9] Martin-Consuegra, F., Oteiza, L., Alonso, C., Cuerdo-Vilches, T. \& Frutos, B., Análisis y propuesta de mejoras para la eficiencia energética del edificio principal del Instituto c.c. Eduardo Torroja-CSIC. Informes de la Construcción, 66, pp. 536, eo43, 2014.

[10] Chang, P.C., Flatau, A. \& Liu, S.C., Review paper: Health monitoring of civil infrastructure. Structural Health Monitoring, 2(3), pp. 257-267, 2003.

[11] Basto, C., Pelà, L. \& Chacón, R., Open-source digital technologies for low cost monitoring of historical constructions. Journal of Cultural Heritage, 25, pp. 31-40, 2017.

[12] AdCiv, Open collaborative design. http://www.adciv.org/Open_collaborative_design. Accessed on: Aug. 2018.

[13] St. Laurent, A.M., Understanding Open Source and Free Software Licensing, O'Reilly Media, 2004.

[14] Gibb, A., Building Open Source Hardware: DIY Manufacturing for Hackers and Makers, Addison-Wesley, pp. 253-277, 2015. Accessed on: Aug. 2018.

[15] Aosong Electronics, AM2302 datasheet. https://akizukidenshi.com/download/ds/ aosong/AM2302.pdf. Accessed on: Aug. 2018.

[16] Aosong Electronics, AM2320 datasheet. https://akizukidenshi.com/download/ds/ aosong/AM2320.pdf. Accessed on: Aug. 2018.

[17] Analog Devices, ADXL345 datasheet. http://www.analog.com/media/en/technicaldocumentation/datasheets/ADXL345.pdf. Accessed on: Aug. 2018.

[18] Texas Instruments, ADS1115 datasheet. http://www.ti.com/lit/ds/symlink/ ads1115.pdf. Accessed on: Aug. 2018. 